Article

\title{
Rural Households' Willingness to Accept Compensation Standards for Controlling Agricultural Non-Point Source Pollution: A Case Study of the Qinba Water Source Area in Northwest China
}

\author{
Xiaoping Li ${ }^{1}$, Wenxin Liu ${ }^{1}$, Yan Yan ${ }^{1}$, Gongyuan Fan ${ }^{2}$ and Minjuan Zhao ${ }^{1, *}$ \\ 1 College of Economics and Management, Northwest A\&F University, Taicheng Road 3, \\ Yangling 712100, China; lxp11742@163.com (X.L.); liuwenxin@nwsuaf.edu.cn (W.L.); \\ yyan@nwsuaf.edu.cn (Y.Y.) \\ 2 Scenic Area Administrative Committee of Wuwei, Guzang road, Liangzhou District, \\ Wuwei 733000, China; GONGYUANHOME@163.com \\ * Correspondence: minjuan.zhao@nwsuaf.edu.cn
}

Received: 21 April 2019; Accepted: 12 June 2019; Published: 14 June 2019

\begin{abstract}
Agricultural non-point source pollution (ANSP) has become one of the main sources of pollution in water source areas. An effective solution to this problem is the use of ecological compensation to encourage rural households to adopt agricultural pollution control measures. This study aims to answer two questions: How much compensation should be given to encourage rural households in water source areas to participate in ANSP control? What factors will influence their participation? In this study, paddy rice planting in water source area has been used as an example aiming to answer these questions. This study used the random parameter logit (RPL) model with survey data from 632 rural households in the Qinba water source area to empirically analyze rural households' willingness to accept compensation for ANSP control and the influencing factors of this willingness. From this information, the compensation standards for ANSP control in a water source area were calculated. The results show that (1) compensation had a significant incentive effect on rural households' willingness to control ANSP. The marginal compensation standard for reducing the use of fertilizer and pesticide was $\$ 3.40 /$ ha and $\$ 2.00 /$ ha, respectively. The compensation standard for not applying chemical fertilizer and pesticide at all was $\$ 540.23 / \mathrm{ha}$. (2) There was heterogeneity in rural households' preference for ANSP control compensation policies. Rural households characterized by younger residents, higher family income, higher perception of the ecological benefits, and higher perception of government policy were more willing to participate in the compensation policy. It is suggested that rural households showed a strong preference for ANSP control policies by considering both of their economic losses and ecological benefits. Our study contributes to the literature by enriching the evaluation method in providing references for the compensation of ANSP control policies
\end{abstract}

Keywords: compensation standard; water source area; agricultural non-point source pollution control; choice experiment

\section{Introduction}

Water source area conservation is key to ensuring water security. However, the ecological security of global water source areas is at risk caused by of agricultural non-point source pollution (ANSP) [1-4]. The use of large amounts of fertilizer and pesticides and the random disposal of agricultural film, straw, livestock manure, and other contaminants all lead to N, P, and other pollutants entering the 
water through runoff and leakage, resulting in ANSP [5]. ANSP not only directly reduces water quality but also causes serious eutrophication. Eutrophication severely degrades aquatic ecosystems and precludes the use of water for industry, agriculture, fishery, recreation, and other purposes [6]. ANSP in water sources endangers the whole basin, and approaches that effectively control ANSP have become critical to water source areas. Globally, measures for ANSP control include management control, organizational design, regulation and taxation [1,7]. At present, the Chinese government primarily relies on top-down administrative measures to protect water source areas. However, for the control of ANSP, this method has several limitations. Firstly, administrative means often impose mandatory restrictions on economic development, so this approach generates major conflicts between environmental protection and economic development [8]. Secondly, because ANSP characteristics are wide-ranging, concealed, random, and difficult to monitor, not only is the cost of monitoring or improving water quality high, but wrongly identifying priority areas might lead to even higher costs $[9,10]$. In fact, economic means are the most effective for controlling ANSP because economic instruments are market-based and sustainable [11]. Therefore, scholars have proposed ecological compensation [12-14] to control ANSP. Based on the compensation, rural households have economic incentives to adopt ANSP control measures, thereby achieving two goals: protecting the environment and developing the economy.

Reasonable compensation standards are central to ensuring the feasibility and effectiveness of the compensation policy. Reasonable compensation standards must not only conform to the principle of minimizing social expenditure but also be sufficient to motivate rural households [15]. At present, the measurement methods of ecological compensation standards are divided into two main categories: the benefit compensation method and the cost compensation method.

The benefit compensation standard is usually considered the "upper limit" of the compensation [16]. The basis of the benefit compensation method is the economic value of ecosystem services. In 1997, Costanza et al. estimated the value of global ecosystem services with the use of market and non-market values, providing a framework for the value of ecosystem services [17]. Then, scholars calculated the ecological value of different ecosystems as a basis for compensation. For example, using the ecosystem service value and location diversity indicators, Sheng Wenping et al. proposed three criteria for ecological compensation for mountain ecological forests in Beijing: main functional zoning, population density, and ecological importance and vulnerability [18]. Zhou Chen et al., using the analysis of land use change in the water source area of the Middle Route Project of the South-to-North Water Transfer from 2002-2010, assessed the ecosystem service value of the water source area. Then, on this basis, they established the upper limit standard of the ecological compensation payment standard [19]. Gao Zhen-bin used the equivalence factor method and the equivalent weight table of ecosystem service function value to determine the theoretical ecological compensation standard of the Dongjiang River Basin. The conclusion was that the appropriate compensation standard of ecosystem services in the Dongjiang River Basin is 171.141 billion yuan [20]. To investigate changes in ecosystem services, Fan Min et al. assigned ecosystem service value per unit area. They found that the total ecosystem service value is about 10,780 billion yuan/year, to which the woodland and grassland ecosystems contributed the most [21].

The cost compensation method is the most widely used compensation principle. The basis of the cost compensation method is opportunity cost, governance cost, replacement cost, etc. Examples of cost compensation perspectives and several studies that applied them are provided in the following. (1) The expected opportunity cost is usually considered the income abandoned by an individual due to an environmental protection action [22,23]. On the basis of the opportunity cost perspective, Thomas et al. calculated a compensation of $\$ 375 /$ (ha.year) to convince every decision maker to maintain a secondary forest in Monte Carlo, Chile [22]. Mashayekhi et al. quantified the economic opportunity cost of conservation for coastal communities living in areas adjacent to mangrove forests in the southern coasts of Iran. The results showed that the local communities had an estimated mean willingness to accept (WTA) of $2026 \mathrm{USD} /($ household.year), which was generally lower than opportunity costs in the 
form of foregone income [23]. (2) The expected governance cost refers to the cost directly invested in the process of ecological protection [24] and pollution treatment [25]. On the basis of the governance cost perspective, Bovenberg et al. explored how the costs of meeting the given aggregate targets for pollution emissions change when imposing the requirement that key pollution-related industries be compensated for potential losses of profit due to the pollution regulation in USA. The conclusion was that the cost of pollution control should be included in the design of sewage discharge fees [26]. (3) The expected replacement cost refers to the cost of repurchasing an asset under existing conditions. Applied to ecological protection, it can be expressed as all of the costs of repairing the environment to a good state [27]. On the basis of the replacement cost perspective, Geng Xiangyan et al. used the Comprehensive Water Quality Index (WQI) to evaluate the water quality of the basin in Shandong Province, China. Due to the difficulty involved with considering the different concentrations of pollutants, a differentiated ecological compensation standard model that incorporated the reset cost was constructed [28].

Rural households are both land managers and beneficiaries of environmental improvement. Neither the benefit compensation method nor the cost compensation method can express the comprehensive benefits that correspond to the dual status of rural households. In recent years, researchers have started to pay attention to the comprehensive benefits of rural households' participation in environmental protection [29,30]; however, as far as we know, there has been no research on the calculation of compensation standards for rural households participating in ANSP in water source areas, particularly in China. The two key questions are: How much compensation should be given to encourage rural households to control ANSP? What factors will affect rural households' willingness to participate in the ANSP control compensation policy? These issues are very important, but they have not attracted enough attention from scholars.

In order to analyze households' preferences, as well as preference heterogeneity, for the ANSP control compensation policy, a choice experiment (CE) survey has been applied to gather the households' voting data, and the random parameter logit (RPL) model has been further used to analyze the collected data. According to paddy rice planting, attributes included in our CE questionnaire are fertilizer reduction, pesticide reduction, agricultural waste recovery rate, and compensation, and the surveyed rural respondents' tasks are to vote for their most preferred option within each choice set. On this basis, the compensation standard was measured. This paper contributes to the literature as follows: the compensation standards which are our investigated households' willingness to accept for the ANSP control policy have been estimated; and farmers' potential opportunity lost caused by ANSP control policy outweighs the compensation standards which proves that farmers also get benefits from the ANSP control policy.

\section{Study Area}

Shaanxi Province, located in the middle reaches of the Yellow River in Central China, is a major grain province in China. The south of Shaanxi Province is an important source of water. It includes the Qinba Mountains and the upper reaches of the Jialing River and the Hanjiang River Basin, a tributary of the Yangtze River. The research area of this study is Ankang City and Hanzhong City, which are located in the south of Shaanxi Province, as shown in Figure 1.

According to the Shaanxi Statistical Yearbook 2017 [31], the populations of Ankang and Hanzhong were 264,000 and 343,000 , respectively. The total agricultural output value of the two cities is $\$ 91.76$ million and \$178.04 million, and the common cultivated land area is 197,300 hectares and 205,150 hectares, respectively. In Ankang city, there are 73 rivers, with a catchment area of more than 100 square kilometers and a total annual runoff of 10.7 billion cubic meters. In Hanzhong City, the main stream of the Hanjiang River is $277.8 \mathrm{~km}$ long, accounting for $18.1 \%$ of the total length of the Hanjiang River; the basin area is 19,692 square kilometers, accounting for $72.3 \%$ of the total land area of Hanzhong City. 


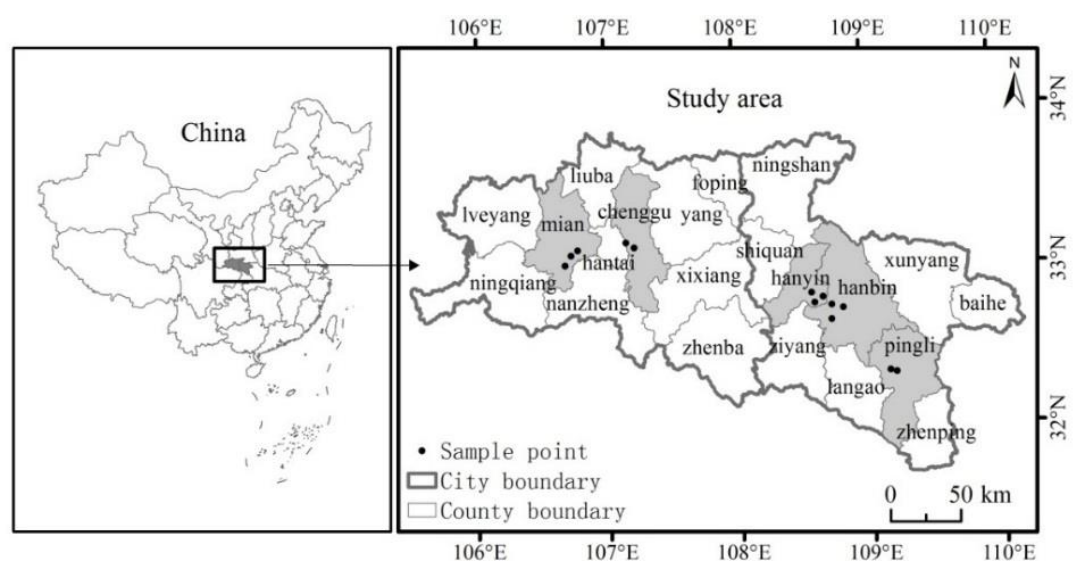

Figure 1. Research area and sampling point distribution.

There are four reasons that Ankang City and Hanzhong City were chosen as research areas. First, in 2008, the Ministry of Environmental Protection and the Chinese Academy of Sciences jointly promulgated the "National Ecological Function Zoning" for the first time to establish an important water conservation area in the Qinba Mountains. Ankang City and Hanzhong City are the central areas of Qinba's water source area. Second, these two cities are the origin of not only the Hanjiang River but also the water conservation area of the Middle Route of South-to-North Water Transfer Project. Third, Ankang City is the pilot demonstration city for the construction of the main functional areas of the country, and Hanzhong City is the pilot area for the construction of the national ecological demonstration area. It is of great significance to carry out ANSP control in these two cities. Fourth, and more importantly, people in Ankang City and Hanzhong City eat rice as their staple food. Rice agricultural activities very easily cause ANSP. In 2017, the rice planting area of Ankang City was 325,400 hectares, and that of Hanzhong City was 989,900 hectares.

ANSP has become the top source of water pollution in the study area [32]. For example, in the Hanjiang River, which is the largest tributary in the research area, nitrogen content was found to be $1.7 \mathrm{mg} / \mathrm{L}$ [33] when it flows out of Ankang City. This is an alarming level of water pollution. In addition, for the period between 2012 and 2014, research found that the fertilizer input of these two cities was above $272.6 \mathrm{~kg} / \mathrm{ha}$ [34], which was much higher than the global average level for the same time period $(120 \mathrm{~kg} / \mathrm{ha})$. The most obvious evidence is that the pre-survey results of the research team showed that the chemical fertilizers input per hectare of rice, wheat, and rape in the sample area were $328.35 \mathrm{~kg}, 297.15 \mathrm{~kg}$, and $319.65 \mathrm{~kg}$, respectively. Given the characteristics of double-cropping rotation in the study area (rice rotates with wheat and oilseed rape, respectively), the annual average input of chemical fertilizers per hectare is $625.5-648 \mathrm{~kg}$, which is $2.78-2.88$ times the internationally recognized upper limit of fertilizer application $(225 \mathrm{~kg} / \mathrm{ha})$. The excessive input of agricultural chemicals poses a challenge to the farmland ecosystem and water resource security.

\section{Methodology}

\subsection{Choice Experiment Design}

A variety of revealed preference and stated preference (SP) valuation methods can be used to determine public preference related to pollution control policies [35-37]. Among them, SP methods predominate over other methods as these methods measure both use and nonuse values [38]. Although contingent valuation (CV) is the commonly used SP technique in pollution control studies [29], the greater flexibility of $\mathrm{CE}$ has raised its growing popularity over recent years in willingness to accept studies $[30,39,40]$. The $C E$ asks the respondents vote for their preferred option among different alternatives described by a bundle of attributes. Of particular relevance is that $\mathrm{CE}$ is capable to estimate shadow prices, or marginal willingness to accept associated with each of the policy attributes [41,42]. 
Attribute and level are the key factors to determine the authenticity and reliability of the choice scenario [43]. ANSP mainly comes from agricultural waste, such as fertilizer, pesticide, agricultural film and crop straw, livestock and poultry urine, rural domestic sewage, domestic refuse, etc. [44]. From these pollutants, after consulting experts in relevant fields and discussing the issue with local agricultural practitioners, the chosen attributes of the CE were, ultimately, fertilizer reduction, pesticide reduction [14], and agricultural waste recovery rate [45].

The CE question scenario is: "Assuming that the government encourages you to use less fertilizer and pesticides in rice cultivation through economic compensation and recycle agricultural wastes, taking into account the ecological benefits, net economic losses from decrease of both investment and production, and compensation benefits of pollution control, which of the following alternatives will you choose?" Each choice set consists of two ANSP control selections and one status quo. The levels of attributes are as follows:

Fertilizer reduction: The international consensus is that excessive fertilizer input is a major source of water pollution [1-3,44]. China's fertilizer input per unit area is $382.5 \mathrm{~kg} / \mathrm{ha}$, much higher than the world average (120 kg/ha), 2.6 times that of the United States, 2.5 times that of the European Union, and 1.93 times the internationally recognized safety limit [46]. Given the above situation, the values of the five levels of fertilizer reduction are no reduction (status quo), reducing by $1 / 4$, reducing by $1 / 2$, reducing by $3 / 4$, and no application (organic) [11].

Pesticide reduction: Excessive application of pesticides has caused serious pollution of soil, air, and water around the world [47]. At present, the unit dosage of pesticides in China is 2.5 times the world average level, and more than $70 \%$ of them are washed into the environment [48]. Given the above situation and the design of fertilizer reduction levels, the values of the five levels of pesticide reduction are no reduction (status quo), reducing by $1 / 4$, reducing by $1 / 2$, reducing by $3 / 4$, and no application (organic).

Agricultural waste recovery rate: Agricultural waste from the process of arable land utilization mainly includes straw, pesticide packaging, plastic film, and so on. They enter soil and water and aggravate ANSP [45]. Agricultural waste recovery technology mainly includes returning straw to the field and fixed-point recovery of pesticide packaging technology, agricultural film, and other wastes. Statistical data show that, in 2016, the utilization rates of straw recovery in Hanzhong and Ankang were $71 \%$ and $57.2 \%$, respectively. The recovery rate of agricultural film in Ankang was $12.8 \%$. On this basis, the levels of the attribute "agricultural waste recovery" are classified as all recovery and partial recovery, and the latter is the benchmark level.

Setting the levels of compensation attributes is a key part of the CE. We made several trips to traditional and organic rice production areas in Ankang City and Hanzhong City. According to preliminary research, it was found that the production of organic rice in the study area, without using chemical fertilizers and pesticides at all, would be reduced by about half. The average yield per hectare of rice under traditional cultivation in the study area is 2382 USD. By our rough estimate, the net economic loss without using chemical fertilizers and pesticides is 1296 USD per hectare (after adjusting for input differences). Therefore, we have set the upper limit for compensation as 1355 USD

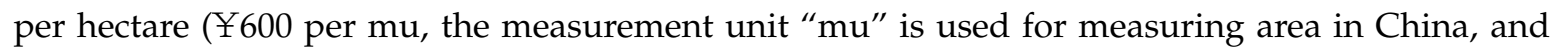
$1 \mathrm{ha}=15 \mathrm{mu}$ ). Combining these numbers with the economic benefits obtained by the rural households due to ANSP control, the levels of compensation are divided into $¥ 0$ per mu (\$0/ha), ¥150 per mu (\$336/ha), ¥200 per mu (\$452/ha), ¥300 per mu (\$677/ha), ¥400 per mu (\$4903/ha), ¥500 per mu (\$1129/ha), and $¥ 600$ per mu (\$1355/ha).

After determining the attributes and their values, the next step for the $\mathrm{CE}$ is to design the choice sets. From previous research experience, each set includes two ANSP control alternatives and one status quo. It is impossible for the participants to choose among 122,500 alternatives, which is the number of permutations according to the levels set above $\left((5 \times 5 \times 2 \times 7)^{2}=122,500\right)$. In this study, all alternatives were generated by Ngene 1.1.1 software (ChoiceMetrics, Sydeny, NSW, Australia). Through orthogonal experimental design, 36 choice sets were finally generated and simultaneously 
been distributed to 12 blocks, each of which had three choice alternatives. Thus, we obtained 12 questionnaire versions and each version included three choice tasks with no dominant or redundant alternatives in each task. Each respondent would be asked to complete only one questionnaire and vote three times within the questionnaire. One specific choice set is shown in Table 1. Selection 3 is the status quo, which is no reduction in fertilizer and pesticide use, partial recovery of agricultural waste, and 0 USD.

Table 1. A sample of the choice set.

\begin{tabular}{cccc}
\hline Attribute & Selection $\mathbf{1}$ & Selection $\mathbf{2}$ & Selection $\mathbf{3}$ \\
\hline Fertilizer reduction & Reducing by 1/4 & Reducing by 1/2 & No reduction of fertilizer \\
Pesticide reduction & Reducing by $1 / 2$ & No reduction & $\begin{array}{c}\text { and pesticides, } \\
\text { part recovery of } \\
\text { agricultural waste }\end{array}$ \\
Agricultural waste recovery rate & No reduction & All classified recovery & $Y 0$ \\
Compensation (Y/(year·mu)) & $¥ 200$ & $¥ 500$ & $\square$ \\
Please choice & $\square$ & $\square$ & $Y$ \\
\hline
\end{tabular}

Note: choose only one alternative to be your favorite among the three on the current choice set by $\square$.

The survey questionnaire is mainly divided into three parts: The first part is the rural households' perception of local ANSP, including the degree of understanding ANSP and their attitude toward ANSP control. The second part is the CE. We introduce ANSP control attributes and their levels, which may change the welfare of the respondents. The third part is the respondents' personal information and family socioeconomic characteristics.

\subsection{RPL Model}

The theoretical basis of CEM is Mcfadden's stochastic utility theory [49], that is, the respondent will choose the most preferred option from a set of choice alternatives. On this basis, this paper assumes that the respondent $i$ chooses alternative $m$ if and only if $U_{i m}>U_{i n}(m, n \in j$ and $m \neq n)$. $U_{i m}$ consists of deterministic utility function $V_{i m}$ and stochastic utility function $\varepsilon_{i m}$, as shown in Equation (1):

$$
U_{i m}=V_{i m}+\varepsilon_{i m}
$$

The deterministic part of $U_{i m}, V_{i m}$ depends on the households' preferences for the attributes $x_{i m}$, as well as the households' socio-economic condition $Z_{i m}$. Assuming a linear represent utility, $V_{i m}$ can be expressed as follows:

$$
V_{i m}=\alpha_{i} A S C_{i m}+\beta_{\mathrm{i}} x_{i m}+\gamma_{i} A S C_{i m} Z_{i m}
$$

Within Equation (2), ASC is the Alternative Specific Constant (ASC), which is a dummy variable representing the non-control alternative. The coefficient of ASC, $\alpha_{i}$ indicates the households' preference for the status quo. The positive $\alpha_{\mathrm{i}}$ means that rural households prefer to choose the status quo, which is the traditional production scheme. On the contrary, the negative $\alpha_{i}$ means that rural households prefer to choose the ANSP control alternatives. The commonly used models for data collected by CE include the multinomial logit (MNL) model, conditional logit (CL) model, and random parameter logit (RPL) model. This paper chooses RPL model, which not only relaxes the assumption of independent and identical distribution of the stochastic $\varepsilon_{i j}$ in the MNL model and the CL model, but also allows for the test of preference heterogeneity, thus reducing the model estimation error [50]. RPL is different from the general logit model the distribution of its random part can be set as any form of mixed distribution, with high flexibility, and the preference heterogeneity of different attribute variables can be tested by the standard deviation of each of the coefficients, which is closer to the reality [51].

Under the assumption of RPL model, the probability of rural households $i$ choosing the $m$ th alternative from all $j$ selections can be expressed as follows: 


$$
P_{\mathrm{im}}=\int \frac{\exp \left(V_{i m}\right)}{\sum_{j} \exp \left(V_{i j}\right)} f(\beta) d \beta
$$

The households' marginal willingness to accept (MWTA) of the ANSP attribute can be calculated as follows:

$$
\mathrm{MWTA}_{a}=I P=-\beta_{a} / \beta_{b}
$$

In Equation (4), $\beta_{a}$ and $\beta_{b}$ represent coefficients of certain ANSP attribute and the coefficients of the compensation attribute, respectively. At the same time, the compensation standard can be derived by households' change in welfare from the change in observed utility, and the specific calculation formula is as follows:

$$
W T A=-\frac{1}{\beta_{b}}\left(V_{0}-V_{1}\right)
$$

In the above formula, $V_{0}$ represents the welfare level of the rural households under the benchmark production mode, and $V_{1}$ represents the welfare level of the rural households in a certain governance scenario.

\subsection{Bias Handling}

The criticism of the CE method has been focused primarily on the reliability and validity of the survey results and various biases $[52,53]$. In the present paper, various measures have been taken to ensure the accuracy and reliability of the investigation by mitigating the hypothetical bias, including: (1) Prior to the questionnaire development, we made several trips to the study area to gather data on the input and output differences between traditional and organic rice cultivation, as this helps to determine a reasonable range for the compensation attribute; (2) a pre-survey, involving 75 rural households ( 15 households from each county) from both Ankang and Hanzhogn cities, was conducted in the case study area to help improve the questionnaire's wording, which made the questionnaire more relevant and understandable; (3) a cheap talk was included to reduce hypothesis bias by describing the background, attributes, and governance level of the study in detail with colored pictures [54-56] (see appendix); (4) the face-to-face interview method was adopted, and before the investigation, our investigators had been trained to describe the background and choice scenario objectively, which helped avoid elicitation bias caused by the investigators; and (5) during the survey, the investigators were asked to wear their identification badges, which convinced the respondents of the survey's scientific purpose.

\subsection{Data}

Our data was obtained from field survey in Ankang City and Hanzhong City. We carried out two surveys in December 2016 and December 2017, separately. During the entire data collecting period, there was no change in policy toward ecological condition and rice production. The results of RPL model by including one period as a dummy variable show that the influence of the data collecting period is not significant. Thus, the data, collected from two separate periods, was combined for further analysis. Considering the agricultural production situation, topography, and the scale of the study area, we selected Hanyin County, Hanbin District, Pingli County, Qixian County, and Chenggu County, and then we randomly selected 13 villages. The research team conducted random sampling. The investigator conducted a one-on-one interview with the head of household to fill out the questionnaire. A total of 670 questionnaires were distributed in two surveys, and 632 valid questionnaires were returned. Among them, the number of valid questionnaires in Ankang City and Hanzhong City were 311 (49.21\%) and 321 (50.79\%), respectively. The specific sampling points are shown in Figure 1. 
Rural households' socio-economic characteristic variables include individual characteristic variables, rural households' capital endowments, and psychological perception variables. Next, we explain the selection basis of these variables.

Firstly, individual characteristics are expressed in terms of age and education attained. Studies have shown that age affects rural households' personal awareness and risk preference [57], and the level of education affects rural households' understanding and learning ability, so these factors may affect rural households' willingness to accept ANSP control measures. The descriptive statistics show that the average age of the head of rural households is 57.13 years old, and the average educational level is 6.36 years. The data are basically consistent with the sampling characteristics of Shaanxi Statistical Yearbook 2017 and Liang Fan [58].

Secondly, the rural households' capital endowment is defined as the number of labor forces, annual household income, and cultivated land. Generally speaking, the number of labor forces and the area of cultivated land greatly affect the rice planting pattern, so it may further affect rural households' willingness to participate in ANSP control. Annual rural household income further affects rural households' participation in environmental policy by affecting their risk tolerance and demand preferences.

Thirdly, the perception variables are defined as heads of households' perceived ecological benefits from the ANSP control [59]. These types of perception can positively stimulate rural households' environmental protection behaviors, which may further influence their expectations for ANSP control compensation.

Table 2 reports the definitions, assignments, and descriptive statistics of these variables.

Table 2. Statistical description of sample variables.

\begin{tabular}{|c|c|c|c|}
\hline Indicator & Definitions and Assignments & Mean & Standard Deviation \\
\hline Age & Age of rural households surveyed & 57.13 & 110.27 \\
\hline Education attained & Years of schooling & 6.36 & 12.94 \\
\hline Number of labor forces & $\begin{array}{l}\text { Number of labor forces in rural households } \\
{[0, \$ 3011)=1 ;[\$ 3011, \$ 6022)=2 ;[\$ 6022, \$ 9033)}\end{array}$ & 2.95 & 1.80 \\
\hline Households' income & $\begin{array}{c}=3 ;[\$ 9033, \$ 12,044)=4 ;[\$ 12,044, \$ 15,055)=5 ; \\
{[\$ 15,055,+\infty)=6}\end{array}$ & 3.12 & 3.08 \\
\hline Cultivated land & Cultivated land of rural households & 4.23 & 19.85 \\
\hline $\begin{array}{l}\text { Ecological benefit } \\
\text { perception }\end{array}$ & $\begin{array}{l}\text { ANSP control has ecological benefits: total } \\
\text { disapproval }=1 ; \text { disapproval }=2 ; \text { general }=3 ; \\
\text { comparative approval }=4 ; \text { total approval }=5\end{array}$ & 3.99 & 1.21 \\
\hline $\begin{array}{l}\text { Government policy } \\
\text { perception }\end{array}$ & $\begin{array}{c}\text { I understand NASP control policy: total } \\
\text { disapproval = } 1 \text {; disapproval }=2 ; \text { general }=3 ; \\
\text { comparative approval }=4 ; \text { total approval }=5\end{array}$ & 2.36 & 1.59 \\
\hline
\end{tabular}

\section{Results and Analysis}

\subsection{Multicollinearity Test of Socio-Economic Variables of Rural Households}

Considering that multicollinearity might exist among the socioeconomic variables of rural households, we carried out the multicollinearity test, detected by the variation inflation factor (VIF). According to the relevant diagnostic criteria, if VIF $>3$, there is a certain degree of multicollinearity between the independent variables; if VIF $>10$, the independent variables are highly correlated [29]. Due to space constraints, only "age" is shown as the diagnostic result (as shown in Table 3). The test results show that the multicollinearity among all independent variables is reasonable. 
Table 3. Multicollinearity diagnostic results.

\begin{tabular}{cccc}
\hline \multirow{2}{*}{ Dependent Variables } & Independent Variables & \multicolumn{2}{c}{ Collinearity Statistics } \\
\cline { 3 - 4 } & & Tolerance & VIF \\
\hline & Number of labor forces & 0.93 & 1.08 \\
& Ecological benefit Perception & 0.95 & 1.05 \\
rural household income & 0.95 & 1.05 \\
Age & Government policy perception & 0.97 & 1.04 \\
& Education attained & 0.97 & 1.04 \\
& Cultivated land & 0.99 & 1.02 \\
Mean VIF & \multicolumn{2}{c}{1.05} \\
\hline
\end{tabular}

\subsection{Influencing Factors of Rural Households' Willingness to Accept Compensation}

In this study, we used mixlogit [60] command in Stata 15.0 (Statacorp, College Station, TX, USA) to analyze the survey data. The results are shown in Table 4. According to the content reported in this paper, combined with the existing research [49], the compensation coefficient was set as a fixed value, and the other attribute variables and socioeconomic characteristic variables were set to follow a normal distribution.

Table 4. Estimation result of RPL model.

\begin{tabular}{|c|c|c|c|c|c|c|}
\hline \multirow{2}{*}{ Indicator } & \multicolumn{3}{|c|}{ Model 1} & \multicolumn{3}{|c|}{ Model2 } \\
\hline & Mean & Std. Error & Std. Dev. & Mean & Std. Error & Std. Dev. \\
\hline ASC & $-29.009^{* * *}$ & 9.081 & $-24.786^{* * *}$ & $-19.875 * *$ & 8.706 & $27.042 * * *$ \\
\hline Compensation & $0.004^{* * *}$ & 0.000 & - & $0.004 * * *$ & 0.000 & - \\
\hline Fertilizer reduction & $-0.006^{* *}$ & 0.002 & 0.006 & $-0.006^{* * *}$ & 0.002 & -0.007 \\
\hline Pesticide reduction & $-0.004 * *$ & 0.002 & $-0.009 *$ & $-0.004 * *$ & 0.002 & $0.013 * * *$ \\
\hline Agricultural waste recovery rate & 0.090 & 0.084 & 0.593 ** & 0.111 & 0.095 & $0.943 * * *$ \\
\hline ASC $\times$ Age & & & & $0.275^{* *}$ & 0.123 & $0.509 * * *$ \\
\hline ASC $\times$ Education attained & & & & -0.250 & 0.205 & 0.097 \\
\hline ASC $\times$ Number of labor forces & & & & -0.579 & 0.504 & $-3.012 * * *$ \\
\hline ASC $\times$ Rural household income & & & & $-0.706^{* *}$ & 0.336 & $1.805^{* * *}$ \\
\hline ASC $\times$ Cultivated land & & & & 0.028 & 0.101 & -0.121 \\
\hline $\begin{array}{c}\text { ASC } \times \text { Ecological benefit } \\
\text { perception }\end{array}$ & & & & $-5.712^{* * *}$ & 1.533 & $-4.914^{* * *}$ \\
\hline $\begin{array}{c}\text { ASC } \\
\text { perception }\end{array}$ & & & & $-11.184^{* * *}$ & 2.909 & 0.481 \\
\hline Log likelihood & & -1354.814 & & & -790.34772 & \\
\hline Prob $>$ chi $^{2}$ & & 0.000 & & & 0.000 & \\
\hline
\end{tabular}

Note: ${ }^{*}, * *$ and ${ }^{* * *}$ indicate the significant level of $10 \%, 5 \%$, and $1 \%$, respectively.

In order to test the robustness of the RPL model estimation results, the model estimates were divided into model 1 with only the attribute variables and model 2 with interaction terms among socioeconomic variables. From the estimation results of model 1 and model 2, we can see that the log-likelihood of the two models reaches a significance level of $1 \%$, and the estimation results of the attribute variables are basically the same. Thus, the results of the model are robust and effective.

The estimated results of model 2 in Table 4 show rural households' willingness to accept and influencing factors of the willingness to accept ANSP control. The detailed analysis results are as follows:

1. ASC. The mean of ASC is negative at the 5\% significance level. This shows that compared with the status quo, rural households in water source areas prefer the ANSP control compensation selection. Rural households are generally willing to accept the ANSP control compensation policy for two reasons: on the one hand, rural households are aware of the damage caused by ANSP and, therefore, have a positive attitude toward ANSP control. On the other hand, the benefit from investing in agriculture is relatively low compared to other sectors and continues to decline. The advantage of 
ANSP control compensation policy is that it not only guarantees agricultural income but also promotes the transfer of the agricultural labor to other higher-income sectors.

2. Attribute variables. The mean of compensation is positive and passes the significance test at the $1 \%$ level; this finding shows that compensation is a positive incentive that increases rural households willingness to participate in ANSP control. The mean of both fertilizer reduction and pesticide reduction are significantly negative, which indicates that farmers are reluctant to take measures to reduce either fertilizer or pesticide.

The standard deviation of a variable's mean reflects the heterogeneity of rural households' preferences. The standard deviation of the fertilizer reduction mean does not pass the significance test, which indicates that the size of fertilizer reduction has no significant impact on rural households' preference. The standard deviation of the pesticide reduction mean is significant at the level of $1 \%$, which indicates that rural households' preference for pesticide reduction is homogeneous, but their preference for the level of pesticide reduction varies. The coefficient of the agricultural waste recovery rate variable is not significant, but the coefficient of standard deviation is significant at the level of $1 \%$, which indicates that rural households have a significant preference for the agricultural waste recovery variable. However, some rural households prefer partial recycling and others prefer the all-recovery classification of recycling. It is this "reverse preference" that causes the lack of significance of the mean, but the significance of the standard deviation, for agricultural waste recovery rate variable

3. The interaction term variable between ASC and socioeconomic characteristics. The mean of the age interaction is significantly positive, indicating that as age decreases, farmers are more willing to participate in ANSP control compensation policy. The reason may be that the current rural old-age security is not perfect. Agricultural output is the main source of income for elderly rural households. They are afraid of the decline of agricultural output and are unwilling to participate in ANSP control.

The mean of rural household income interaction is significantly negative, indicating that, as income increases, willingness to participate in ANSP increases. The possible reason for this result is that, on the one hand, the economic loss of reducing fertilizer and pesticide application has little negative impact on high-income rural households. On the other hand, the demand of high-income rural households is different from that of low-income rural households. High-income rural households often pay more attention to the quality of life and environmental safety, so they are more willing to participate in ANSP control.

The mean of the ecological benefit perception interaction is significantly negative, which indicates that farmers with high ecological benefit awareness are more willing to participate in ANSP control compensation policy when other conditions are unchanged. The reason may be that farmers with high awareness of ecological benefits are often aware of the positive role of ANSP control in environmental protection and human health.

The mean of government policy perception interaction is significantly negative, which indicates that farmers with high ANSP control policy awareness are more willing to participate in ANSP control compensation policy with the other conditions unchanged. The reason may be that, on the one hand, farmers with high ANSP control policy perception have a better understanding of its significance and sustainability. On the other hand, most rural households with high awareness of policy are characterized by their caring about current affairs and abundant access to information. These rural households usually have a higher awareness of public responsibility. They are "activists" in the promotion of environment protection policies, so they have a higher enthusiasm for ANSP control compensation policy.

The standard deviation of the age interaction coefficient, family income level coefficient, and ecological benefit perception degree coefficient is significant at $1 \%$, which indicates that the three variables of age, rural household income, and ecological benefit perception have the same influence on rural households' willingness to accept ANSP ecological compensation policy, but there are some differences in the strength of their influences. The standard deviation of government policy perception is 
not significant, which indicates that regardless of whether the perception degree of ANSP control policy is high or low, there is no difference in rural households' preference for ANSP control compensation.

\subsection{Compensation Standard Calculation}

According to Equations (4) and (5), combined with the RPL model estimation results in Table 3, the marginal compensation for different attributes and ANSP control scenarios have been estimated, as shown in Table 5.

Table 5. Compensation for different attributes and control scenarios.

\begin{tabular}{|c|c|c|c|c|c|c|}
\hline \multirow{2}{*}{ Attribute } & \multicolumn{2}{|c|}{$\begin{array}{l}\text { Marginal Compensation } \\
\text { Standard }\end{array}$} & \multicolumn{2}{|c|}{$\begin{array}{l}\text { Compensation of World } \\
\text { Average }\end{array}$} & \multicolumn{2}{|c|}{$\begin{array}{c}\text { Compensation of Organic } \\
\text { Production }\end{array}$} \\
\hline & $\begin{array}{l}\text { Attribute } \\
\text { Change }\end{array}$ & $\begin{array}{l}\text { Compensation } \\
\text { Standard }(\$ / \text { ha) }\end{array}$ & $\begin{array}{l}\text { Attribute } \\
\text { Change }\end{array}$ & $\begin{array}{l}\text { Compensation } \\
\text { Standard }(\$ / \text { ha) }\end{array}$ & $\begin{array}{l}\text { Attribute } \\
\text { Change }\end{array}$ & $\begin{array}{l}\text { Compensation } \\
\text { Standard }(\$ / \text { ha) }\end{array}$ \\
\hline $\begin{array}{l}\text { Fertilizer } \\
\text { reduction }\end{array}$ & $\begin{array}{c}\text { Reducing by } \\
1 \%\end{array}$ & 3.40 & $\begin{array}{c}\text { Reducing by } \\
60 \%\end{array}$ & 204.06 & $\begin{array}{l}\text { Reducing by } \\
100 \%\end{array}$ & 340.09 \\
\hline $\begin{array}{l}\text { Pesticide } \\
\text { reduction }\end{array}$ & $\begin{array}{l}\text { Reducing by } \\
1 \%\end{array}$ & 2.00 & $\begin{array}{l}\text { Reducing by } \\
73 \%\end{array}$ & 146.10 & $\begin{array}{l}\text { Reducing by } \\
100 \%\end{array}$ & 200.14 \\
\hline Total & & 5.40 & & 350.16 & & 540.23 \\
\hline
\end{tabular}

It can be seen from Table 4 that the marginal compensation standards for reducing fertilizer and pesticide are $\$ 3.40 /$ ha and $\$ 12.00 /$ ha, respectively. As the farmers have a deep understanding of the gains and losses from using pesticide and fertilizer, a lower marginal compensation for pesticide may be caused by both fertilizers being more importance to the output and pesticides being more toxic to humans and livestock [61]. The amount of fertilizer and pesticide used per unit area by Chinese farmers is well above the global average. According to the statistics, China should use $73 \%$ less chemical fertilizer and $60 \%$ less pesticide to keep in line with the world average, and the compensation criteria would be $\$ 350.16 /$ ha based on the implicit prices in Table 5. Moreover, for organic production without the application of fertilizers and pesticides, the compensation standard would be $\$ 540.23 / \mathrm{ha}$, including \$340.09/ha and \$200.14/ha for fertilizers and pesticide, respectively.

\subsection{Reasonableness Test of Compensation Standard}

(1) Comparison with the opportunity cost of cultivated land: As above, the opportunity cost of ANSP control is roughly $\$ 1296 /$ ha for organic production. The cost is significantly greater than the compensation standard for cultivated land organic production based on the perspective of rural households' acceptance for compensation (\$540.23/ha). This result proves that the monetary result is the lower limit of compensation; on the other hand, it also indicates a large benefit of rural households can be derived from ANSP control, which is about $\$ 763 /$ ha. (2) Comparison with fallow compensation standards: The aim of fallow policy is to prevent water and metal pollution. The compensation standard for fallow, which of cause using no fertilizer or pesticide, is $\$ 1581 /$ ha, is much larger than the compensation standard estimated in our research. This result confirms the rationality of our estimated compensation standard and the advantages of easing the financial burden of the state.

\section{Conclusions and Discussion}

\subsection{Discussion}

In this paper, our estimated compensation standard for rural households' acceptation of ANSP control is a combination of the economic loss and the ecological benefits. This compensation standard can be used to improve the compensation efficiency, realize the principle of minimizing social expenditure, and helping to solve the predicament of rural households' low enthusiasm toward environmental protection under the state's fiscal constraints [17]. However, the compensation standard has not considered the positive ecological externalities brought by ANSP control to the whole region, 
and is unfair to rural households. In view of this, this paper suggests that our estimated compensation standard in this paper should be used as the lower limit of compensation when designing ANSP control policy. Where possible, the government should offer more fiscal stimulus by properly raising the compensation standard, particularly in poor rural areas and for low-income households [62,63].

Moreover, CE provides implications towards the design of ANSP control policy. Rural households' WTA for each attribute can be used by policy-makers to formulate the most cost-effective ANSP control policies. Additionally, the variation of rural households' preferences indicated the importance of policy advocacy. The government should facilitate rural households' engagement and collective action in ANSP control by means of public education, relationship building through various traditional, or modern media.

\subsection{Conclusions and Policy Implication}

The ecological security of the Qinba water source area is not only an important part of the China's building of ecological civilization but also closely related to the water security of Henan, Hebei, Beijing, Tianjin, etc. In order to prevent and control ANSP in Qinba, this paper reports the analysis of rural households' WTA compensation policy and the corresponding compensation standard. First and most importantly, compensation exerts a significant incentive effect on rural households' willingness to participate in ANSP control compensation policy. The marginal compensation standards for reducing fertilizers and pesticides are $\$ 3.40 /$ ha and $\$ 2.00 /$ ha, respectively. The compensation standard for the organic production mode is $\$ 540.23 / \mathrm{ha}$. The policy implications of this conclusion are that rural households' willingness should be included in the process of designing the compensation policy. Moreover, the compensation standard should also consider rural households' economic loss and ecological benefit.

Secondly, rural households are more willing to participate in the compensation policy if they are characterized by younger residents, higher rural household income, higher perception of ecological benefits, and higher perception of government policy of ANSP control. This means that rural households' willingness to participate in ANSP control is not only limited by individual and family endowments but also by their environmental awareness and policy-making environment. The implication of this conclusion is that the government could make use of various traditional or modern media (such as network, satellite TV, radio, etc.) to educate rural households on environmental protection in an effort to enhance their enthusiasm to participate in ANSP control.

Author Contributions: Conceptualization, M.Z. and X.L.; methodology, W.L.; writing—original draft preparation, X.L.; writing-review and editing, Y.Y. and G.F.; Resource, M.Z.

Funding: This research was funded by the Major Research Projects of the National Social Science Fund of China (15ZDA052).

Acknowledgments: We would like to thank MDPI for polishing this paper. We also appreciate the constructive suggestions and comments on the manuscript from the reviewers and editors.

Conflicts of Interest: No potential conflict of interest was reported by the authors.

\section{References}

1. Panagopoulos, Y.; Makropoulos, C.; Mimikou, M. Reducing surface water pollution through the assessment of the cost-effectiveness of BMPs at different spatial scales. J. Environ. Manag. 2011, 92, 2823-2835. [CrossRef] [PubMed]

2. Jabbar, F.K.; Grote, K. Statistical assessment of nonpoint source pollution in agricultural watersheds in the Lower Grand River watershed, MO, USA. Environ. Pollut. Res. 2019, 26, 1487-1506. [CrossRef] [PubMed]

3. Jin, S.Q.; Wu, Y. Is agricultural non-point source pollution the primary cause of water pollution? Test Based on the Data of Huaihe River. Chin. Rural Econ. 2014, 9, 71-81.

4. Junakova, N.; Balintova, M.; Vodicka, R.; Junak, J. Prediction of Reservoir Sediment Quality Based on Erosion Processes in Watershed Using Mathematical Modelling. Environments 2018, 5, 6. [CrossRef] 
5. Carpenter, S.R.; Caraco, N.F.; Correll, D.L.; Howarth, R.W.; Sharpley, A.N.; Smith, V.H. Nonpoint pollution of surface waters with phosphorus and nitrogen. Ecol. Appl. 1998, 8, 559-568. [CrossRef]

6. Halliday, S.J.; Skeffington, R.A.; Bowes, M.J.; Gozzard, E.; Newman, J.R.; Loewenthal, M.; Palmer-Felgate, E.J.; Jarvie, H.P.; Wade, A.J. The Water quality of the River Enborne, UK: Observations from high-frequency monitoring in a rural, lowland river system. Water 2014, 6, 150-180. [CrossRef]

7. Power, M.E.; Brozovic, N.; Bode, C.; Zilberman, D. Spatially Explicit Tools for Understanding and Sustaining Inland Water Ecosystems. Front. Ecol. Environ. 2005, 3, 47-55. [CrossRef]

8. Ge, Y.X.; Liang, L.J.; Jie, Y.M. Study on the Construction and Operation of Ecological Compensation Mechanism for Water Source. Issues Agric. Econ. 2006, 9, 22-28.

9. Hu, H.Y.; Huang, G.R. Monitoring of Non-Point Source Pollutions from an Agriculture Watershed in South China. Water 2014, 6, 3828-3840. [CrossRef]

10. Psaltopoulos, D.; Wade, A.J.; Skuras, D.; Kernan, M.; Tyllianakis, E.; Erlandsson, M. False positive and false negative errors in the design and implementation of agri-environmental policies: A case study on water quality and agricultural nutrients. Sci. Total Environ. 2017, 575, 1087-1099. [CrossRef]

11. Vergano, L.; Nunes, P.A.L.D. Analysis and evaluation of ecosystem resilience: An economic perspective with an application to the Venice lagoon. Biodivers. Conserv. 2007, 16, 3385-3408. [CrossRef]

12. Engel, S.; Pagiola, S.; Wunder, S. Designing payments for environmental services in theory and practice: An overview of the issues. Ecol. Econ. 2008, 65, 663-674. [CrossRef]

13. Wu, Z.N.; Guo, X.; Lv, C.M.; Wang, H.L.; Di, D.Y. Study on the quantification method of water pollution ecological compensation standard based on emergy theory. Ecol. Indic. 2017, 92, 189-194. [CrossRef]

14. Nesha, B.B.; James, C.R.S.; Mette, T.; Klaus, H. Evaluating farmers' likely participation in a payment programme for water quality protection in the UK uplands. Reg. Environ. Chang. 2013, 13, 633-647.

15. Liu, M.C.; Xiong, Y.; Yuan, Z.; Min, Q.W.; Sun, Y.H.; Fuller, A.M. Standards of ecological compensation for traditional eco-agriculture: Taking rice-fish system in Hani terrace as an example. J. Mt. Sci. 2014, 11, 1049-1059. [CrossRef]

16. Claassen, R.; Cattaneo, A.; Johansson, R. Cost-effective design of agri-environmental payment programs: U.S. experience in theory and practice. Ecol. Econ. 2008, 65, 737-752. [CrossRef]

17. Costanza, R.; Ralph, A.; Rudolf, D.G.; Stephen, F.; Monica, G.; Bruce, H.; Karin, L.; Shahid, N.; Robert, V.; Jose, P.; et al. The value of the world's ecosystem services and natural capital. Nature 1997, 15, 253-260. [CrossRef]

18. Sheng, W.P.; Zhen, L.; Xie, G.D.; Xiao, Y. Determining eco-compensation standards based on the ecosystem services value of the mountain ecological forests in Beijing, China. Ecosyst. Serv. 2017, 26, 422-430. [CrossRef]

19. Zhou, C.; Ding, X.D.; Li, G.P.; Wang, H.Z. Ecological compensation standards in the water source area of the middle route project of the South-North water transfer project. Resour. Sci. 2015, 37, 792-804.

20. Gao, Z.B.; Wang, X.L.; Su, J.; Chen, Z.F.; Zheng, M.X.; Sun, Y.Y.; Ji, D.F. Ecological Compensation of Dongjiang River Basin Based on Evaluation of Ecosystem Service Value. J. Ecol. Rural Environ. 2018, 34, 563-570.

21. Fan, M.; Chen, L. Spatial characteristics of land uses and ecological compensations based on payment for ecosystem services model from 2000 to 2015 in Sichuan Province, China. Ecol. Inform. 2019, 50, 162-183. [CrossRef]

22. Knoke, T.; Hildebrandt, P.; Klein, D.; Mujica, R.; Moog, M.; Mosandl, R. Financial compensation and uncertainty: Using mean-variance rule and stochastic dominance to derive conservation payments for secondary forests. Can. J. For. Res. 2008, 38, 3033-3046. [CrossRef]

23. Mashayekhi, Z.; Danehkar, A.; Sharzehi, G.A.; Majed, V. Coastal Communities WTA Compensation for conservation of mangrove forests: A choice experiment approach. Knowl. Manag. Aquat. Ecosyst. 2016, 417, 1-10. [CrossRef]

24. Moss, L.R. Local governments reduce costs through pollution prevention. J. Clean. Prod. 2008, 16, 704-708. [CrossRef]

25. Lescot, J.M.; Bordenave, P.; Petit, K.; Leccia, O. A spatially-distributed cost-effectiveness analysis framework for controlling water pollution. Environ. Model. Softw. 2013, 41, 107-122. [CrossRef]

26. Bovenberg, A.L.; Goulder, L.H.; Jacobsen, M.R. Costs of alternative environmental policy instruments in the presence of industry compensation requirements. J. Public Econ. 2008, 92, 1236-1253. [CrossRef]

27. Kopp, R.J.; Krupnick, A. Agricultural Policy and the Benefits of Ozone Control. Am. J. Agric. Econ. 1987, 69, 956-962. [CrossRef] 
28. Geng, X.Y.; Ge, Y.X.; Zhang, H.N. Study on ecological compensation standard of watershed based on reset cost. China Popul. Resour. Environ. 2018, 28, 140-147.

29. He, K.; Zhang, J.B.; Zeng, Y.M.; Zhang, L. Households' willingness to accept compensation for agricultural waste recycling: Taking biogas production from livestock manure waste in Hubei, P.R. China as an example. J. Clean. Prod. 2016, 131, 410-420. [CrossRef]

30. Mutandwa, E.; Grala, R.K.; Petrolia, D.R. Estimates of willingness to accept compensation to manage pine stands for ecosystem services. For. Policy Econ. 2019, 102, 75-85. [CrossRef]

31. Shaanxi Statistical Bureau. Shaanxi Statistical Yearbook 2017; China Statistics Publishing House: Beijing, China, 2018.

32. Zhu, Y.Y.; Liu, Y.; Zhou, B.H.; Jiang, Q.F.; Wu, D.W. The temporal and spatial distribution of nitrogen in Danjiangkou Reservoir Watershed. Environ. Monit. China 2016, 32, 50-57.

33. Zhu, Y.Y.; Tian, J.J.; Li, H.L.; Jiang, Q.F.; Liu, Y. Water qaulity assessment and pollution profile identification of Danjiangkou Reservoir, China. J. Agro-Environ. Sci. 2016, 35, 139-147.

34. Zhao, Z.P.; Yan, S.; Tong, Y.A. Eco-environmental status assessment and treatment measure in the upper Hanjing River Basin. Bull. Soil Water Conserv. 2012, 32, 32-36.

35. Urama, K.C.; Hodge, I.D. Are stated preferences convergent with revealed preferences? Empirical evidence from Nigeria. Ecol. Econ. 2006, 59, 24-37. [CrossRef]

36. Guignet, D. The impacts of pollution and exposure pathways on home values: A stated preference analysis. Ecol. Econ. 2012, 82, 53-63. [CrossRef]

37. Yao, L.Y.; Deng, J.F.; Johnston, R.J.; Khan, I.; Zhao, M.J. Evaluating willingness to pay for the temporal distribution of different air quality improvements: Is China's clean air target adequate to ensure welfare maximization? Can. J. Agric. Econ./Rrevue Can. D'Agroecon. 2018, 67, 215-232. [CrossRef]

38. Schultz, E.T.; Johnston, R.J.; Segerson, K.; Besedin, E.Y. Integrating Ecology and Economics for Restoration: Using Ecological Indicators in Valuation of Ecosystem Services. Restor. Ecol. 2012, 20, 304-310. [CrossRef]

39. Garcia, J.H.; Cherry, T.L.; Kallbekken, S.; Torvanger, A. Willingness to accept local wind energy development: Does the compensation mechanism matter? Energy Policy 2016, 199, 165-173. [CrossRef]

40. Bateman, I.J.; Day, B.H.; Jones, A.P.; Jude, S. Reducing gain-loss asymmetry: A virtual reality choice experiment valuing land use change. J. Environ. Econ. Manag. 2009, 58, 106-118. [CrossRef]

41. Rolfe, J.; Bennett, J. The impact of offering two versus three alternatives in choice modelling experiments. Ecol. Econ. 2009, 68, 1140-1148. [CrossRef]

42. Yao, L.Y.; Zhao, M.J.; Cai, Y.; Yin, Z.W. Public Preferences for the Design of a Farmland Retirement Project: Using Choice Experiments in Urban and Rural Areas of Wuwei, China. Sustainability 2018, 10, 1579. [CrossRef]

43. Zhao, M.J.; Johnston, R.J.; Schultz, E.T. What to value and how? Ecological indicator choices in stated preference valuation. Environ. Resour. Econ. 2013, 56, 3-25. [CrossRef]

44. Briassoulis, D.; Hiskakis, M.; Babou, E.; Antiohos, S.K.; Papadi, C. Experimental investigation of the quality characteristics of agricultural plastic wastes regarding their recycling and energy recovery potential. Waste Manag. 2012, 32, 1075-1090. [CrossRef] [PubMed]

45. Sims, J.T.; Goggin, N.; Mcdermott, J. Nutrient management for water quality protection: Integrating research into environmental policy. Water Sci. Technol. 1999, 39, 291-298. [CrossRef]

46. Ministry of Agriculture of the People's Republic of China. Action Plan for the Zero Increase of Fertilizer Use in 2020 [EB/OL]. (2017-2003-07) [2015-2003-18]. Available online: http://jiuban.moa.gov.cn/zwllm/tzgg/tz/ 201503/t20150318_4444765.htm (accessed on 1 April 2019).

47. Dahshan, H.; Megahed, A.M.; Abdelall, A.M.; Abdelkader, M.A.; Nabaw, E.; Elbana, M.H. Monitoring of pesticides water pollution-The Egyptian River Nile. Iran. J. Environ. Health Sci. Eng. 2016, 14, 1-15. [CrossRef] [PubMed]

48. Zhu, D.; Kong, X.; Gu, J.P. Irrational Equilibrium of Overuse of Pesticides by Farmers: Evidence from Farmers in Southern Jiangsu. Chin. Rural Econ. 2014, 8, 17-29.

49. Mcfadden, D. Conditional logit analysis of qualitative choice behavior. In Frontiers in Econometrics; Zarembka, P., Ed.; Academic Press: New York, NY, USA; pp. 105-142.

50. Xu, T.; Zhao, M.J.; Qiao, D.; Yao, L.Y.; Yan, Y. Subsidy policy design of two oriented technology based on farmer households' preference. J. Northwest AEF Univ. (Soc. Sci. Ed.) 2018, 18, 109-118.

51. Quan, S.W. Advances in Selective Experimental Methods. Econ. Inf. 2016, 1, 127-141. 
52. Riccarda, M.; Roberta, R.; Sandra, N. Testing hypothetical bias with a real choice experiment using respondents' own money. Eur. Rev. Agric. Econ. 2014, 41, 25-46.

53. Train, K.; Wilson, W.W. Estimation on stated-preference experiments constructed from revealed-preference choices. Transp. Res. Part B Methodol. 2008, 42, 191-203. [CrossRef]

54. Brown, T.C.; Ajzen, I.; Hrubes, D. Further tests of entreaties to avoid hypothetical bias in referendum contingent valuation. J. Environ. Econ. Manag. 2003, 46, 353-361. [CrossRef]

55. List, J.A. Do explicit warnings eliminate the hypothetical bias in elicitation procedures? Evidence from field auctions for sportscards. Am. Econ. Rev. 2001, 91, 1498-1507. [CrossRef]

56. Silva, A.; Nayga, R.M.; Campbell, B.L.; Park, J.L. Can perceived task complexity influence cheap talk's effectiveness in reducing hypothetical bias in stated choice studies? Appl. Econ. Lett. 2012, 19, 1711-1714. [CrossRef]

57. Li, J.G.; Gao, Y.M.; Zang, J.M. The impact of farmers' risk awareness on land transfer decision making behavior. J. Agrotech. 2014, 11, 21-30.

58. Liang, F.; Zhu, Y.C. Analysis of farmer's vulnerability to poverty from the perspective of resource endowment. J. Northwest AEF Univ. (Soc. Sci. Ed.) 2018, 18, 131-140.

59. Romy, G. Motivations and attitudes influence farmers' willingness to participate in biodiversity conservation contracts. Agric. Syst. 2015, 137, 154-165.

60. Hole, A.R. Fitting mixed logit models by using maximum simulated likelihood. Stata J. 2007, 7, 388-401. [CrossRef]

61. Cai, J. Pesticide Packaging waste recycling: Support attitude and model choice. Res. Econ. Manag. 2013, 12, $67-74$.

62. Kristrom, B.; Riera, P. Is the income elasticity of environmental improvements less than one. Environ. Resour. Econ. 1996, 7, 45-55. [CrossRef]

63. Tyllianakis, E.; Skuras, D. The income elasticity of Willingness-To-Pay (WTP) revisited: A meta-analysis of studies for restoring Good Ecological Status (GES) of water bodies under the Water Framework Directive (WFD). J. Environ. Manag. 2016, 182, 531-541. [CrossRef]

(C) 2019 by the authors. Licensee MDPI, Basel, Switzerland. This article is an open access article distributed under the terms and conditions of the Creative Commons Attribution (CC BY) license (http://creativecommons.org/licenses/by/4.0/). 